\title{
In vitro and in vivo anticancer effects of two quinoline-platinum(II) complexes on human osteosarcoma models
}

\author{
Maria Carolina Ruiz ${ }^{1,2} \cdot$ Agustina Resasco $^{3}$ - Ana Laura Di Virgilio ${ }^{1,2} \cdot$ Miguel Ayala $^{3} \cdot$ Isabel Cavaco $^{4} \cdot$ Silvia Cabrera $^{5}$. \\ Jose Aleman ${ }^{6} \cdot$ Ignacio Esteban León ${ }^{2}$ (1)
}

Received: 10 August 2018 / Accepted: 7 January 2019 / Published online: 19 January 2019

(C) Springer-Verlag GmbH Germany, part of Springer Nature 2019

\begin{abstract}
Platinum-based drugs, mainly cisplatin, are used for the treatment of several solid tumors such as OS. However, cisplatin treatment often results in the development of chemoresistance, leading therapeutic failure. We have previously reported that platinum complexes containing 8-hydroxyquinoline ligands have good antitumor activity against different cancer cell lines and with a different and better cytotoxic profile than cisplatin. Here, the anticancer properties of two different quinoline-platinum complexes $\left[\mathrm{Pt}(\mathrm{Cl})_{2}\right.$ (quinoline)(dmso)] (1) $[\mathrm{PtCl}(8-O$-quinoline $)(\mathrm{dmso})](2)$ on in vitro (2D and 3D) and in vivo models (xenograft tumor of human osteosarcoma in mice) are presented. In this order, $[\mathrm{PtCl}(8-O$-quinoline)(dmso)] (2) impaired cell viability to have a more pronounced antitumor effect than cisplatin on MG-63 osteosarcoma cells ( $\mathrm{IC}_{50} 4 \mu \mathrm{M}$ vs. $\left.39 \mu \mathrm{M}\right)$. Besides, $[\mathrm{PtCl}(8-O$-quinoline $)(\mathrm{dmso})]$ (2) increased $\mathrm{ROS}$ production in a dose-manner response and this compound induced early and late apoptotic fractions of human osteosarcoma cells. Finally, [ $\mathrm{PtCl}(8-O$-quinoline)(dmso)] (2) decreased the cell viability of multicellular spheroids and reduced the tumor volume on athymic nude mice $\mathrm{N}: \mathrm{NIH}(\mathrm{S})$ Fox $1^{\text {nu }}$ without inducing side effects. In this way, $[\mathrm{PtCl}(8-O$-quinoline)(dmso)] (2) did not alter the normal cytoarchitecture of liver and kidney and the blood biomarkers (GPT, GOT, uremia, and creatinine) did not suffer modifications. Taken together, our data indicate that these compounds showed a better anticancer performance than cisplatin on in vitro and in vivo studies. These results showed the importance of chelation in the antitumor properties, suggesting that the $[\mathrm{PtCl}(8-O$-quinoline $)(\mathrm{dmso})](2)$ might be a promising agent for the treatment of human osteosarcoma tumors resistant to cisplatin.
\end{abstract}

Keywords Platinum $\cdot$ Osteosarcoma $\cdot$ Spheroids $\cdot$ Apoptosis

Electronic supplementary material The online version of this article (https://doi.org/10.1007/s00280-019-03773-x) contains supplementary material, which is available to authorized users.

Ignacio Esteban León

ileon@biol.unlp.edu.ar

1 Chair of Pathologic Biochemistry, Exact School Sciences, National University of La Plata, 1900 La Plata, Argentina

2 Inorganic Chemistry Center (CONICET-UNLP) Exact School Sciences, National University of La Plata, 1900 La Plata, Argentina

3 Lab Experimental Animals, Veterinary School Sciences, National University of La Plata, 1900 La Plata, Argentina

4 Chemistry, Biochemistry and Pharmacy Department, Algarve University, 8005-139 Faro, Portugal

5 Inorganic Chemistry Department, Autonomous University of Madrid, 28049 Madrid, Spain

6 Organic Chemistry Department, Universidad Autónoma de Madrid, 28049 Madrid, Spain

\section{Introduction}

It is widely known that cisplatin, carboplatin, and oxaliplatine are the most important and successful metallodrugs used in the clinic [1]. Cisplatin has been effective for the treatment of solid human tumors, including osteosarcoma (OS), even though severe side effects, like nephrotoxicity and hematological toxicity, and tumor resistance were observed after its administration for long periods of time [2]. This solid tumor is a primary bone malignant tumor and the most common bone tumor in children and young adults [3], so a better understanding of the mechanisms underlying the clinical expression of OS and the identification of novel chemotherapeutic drugs for a more effective treatment are of importance to improve the welfare and survival of these patients. In this way, different ligands and combined therapies have been employed for chemotherapy, such as combinations of caffeine and xanthine derivatives $[4,5]$, but the 
prognoses of recurrent osteosarcoma was moderate (longterm survival of $>20 \%$ ) $[6,7]$. Other more recent platinum complexes based on ionic platinum complexes using bisphosphonates as ligands (because of their strong affinity for calcium) have been studied with the moderate results [8-10].

More recently, Tsuchiya et al. [11] have described the synthesis of new ionic platinum complexes which can be effective as antitumor drugs. These platinum complexes include in their structure polyaromatic ligands as phenanthroline derivatives, while the other platinum complexes used ligands derived from bisphosphonates. The main characteristic of these platinum drugs is related to the ionic character, even in the cases that some Farrell's group who developed poly-cationic platinum complexes that later failed in clinical phases [12].

On the other hand, quinolines and derivatives are a family of ligands with multiple biological activities such as antineurodegenerative, antiviral, antibacterial, antioxidant, and anticancer, among others $[13,14]$. In this case, 8 hydroxyquinoline (8HQ) has potent coordinating ability and good metal recognition properties, which means that it is widely used for analytical applications as well as for metal chelation [15]. Besides, $8 \mathrm{HQ}$ is the most interesting one to be explored, due to its multifunctional and diverse properties related to the therapeutic potentials $[13,15]$.

Recently, we have developed a new family of antitumor platinum complexes, that used different substituted 8-hydroxyquinoline derivatives as ligands (which have been used in medicinal chemistry as polycyclic aromatics compounds (PACS) [16]. The anticancer activity of these complexes was quite active against a panel of representative human tumor cell lines. The use of $2 \mathrm{D}$ cell in culture models to test potential antitumor drugs is one of the most suitable employed assays. Nevertheless, in the 2D cell culture models, the cells are more likely to be affected by the drug under evaluation than in more representative 3D models of tumors (multicellular spheroids) [17, 18].

The multicellular spheroids (MCS), as a 3D model, simulate the avascular state of an in vivo tumor and it is a successful model to study the cellular uptake of antitumor-based drugs [19-21].

Based on our previous studies and from others on the use of platinum drugs against osteosarcoma our hypothesis is based on the assumption that the ionic nature of the platinum complex is critical for the activity of these drugs in the bone tumor and the chelation of the aromatic group (hydroxyquinoline) has an important role [16]. To clarify these issues, we present here the biological evaluation of a quinoline-platinum complex $1\left[\mathrm{Pt}(\mathrm{Cl})_{2}\right.$ (quinoline)(dmso)] formed by monodentate aromatic ligand and the chelate complex 2 [ $\mathrm{PtCl}(8-O$-quinoline $)(\mathrm{dmso})]$ formed by 8 -hydroxyquinolate ligand on 2D and 3D spheroids human osteosarcoma cells. In addition, our investigations on in vivo antitumor effects of complex $\mathbf{2}$ on a xenograft mice model of osteosarcoma are also presented.

\section{Materials and methods}

\section{Materials}

Tissue culture materials were purchased from Corning (Princeton, NJ, USA), Dulbecco's Modified Eagles Medium (DMEM), TrypLETM from Gibco (Gaithersburg, MD, USA), and fetal bovine serum (FBS) from Internegocios SA (Argentina). Dihydrorhodamine 123 (DHR) was purchased from Molecular Probes (Eugene, OR). Annexin V, fluorescein isothiocyanate (FITC), and propidium iodide (PI) were from Invitrogen Corporation (Buenos Aires, Argentina). SYBR Green and Low melting point agarose were purchased from Invitrogen Corporation (Buenos Aires, Argentina). JC1 was provided by Biomol International (USA). The $\mathrm{cis}$ $\mathrm{PtCl}_{2}(\mathrm{DMSO})_{2}$ complex was synthesized according to the literature procedure [22].

\section{Synthesis of platinum complexes: 1 and 2 [16]}

\section{General methods}

NMR spectra were acquired on a Bruker 300 spectrometer, running at 300,75 and $64.5 \mathrm{MHz}$ for ${ }^{1} \mathrm{H},{ }^{13} \mathrm{C}$, and ${ }^{195} \mathrm{Pt}$, respectively. Chemical shifts $(\delta)$ are reported in ppm relative to residual solvent signals (DMSO- $\mathrm{d}_{6}: 2.50 \mathrm{ppm}$ for ${ }^{1} \mathrm{H}$ NMR; $\mathrm{CD}_{2} \mathrm{Cl}_{2}: 5.32$ ppm for ${ }^{1} \mathrm{H}$ NMR, 53.84 for ${ }^{13} \mathrm{C} \mathrm{NMR}$ ). ${ }^{13} \mathrm{C}$ NMR spectra were acquired on a broadband decoupled mode. ${ }^{195} \mathrm{Pt}$ NMR spectra were obtained with chemical shifts reported in ppm downfield relative to the external reference $1.0 \mathrm{M} \mathrm{Na}_{2} \mathrm{PtCl}_{6}$ in $\mathrm{D}_{2} \mathrm{O}$. Melting points were measured using a Gallenkamp apparatus in open capillary tubes.

\section{General procedure for the synthesis of compounds 1 and 2}

Compounds 1 and 2 were synthesized according to our previously reported results [16].

$\left[\mathrm{Pt}(\mathrm{Cl})_{2}\right.$ (quinoline)(dmso)] (1). The product was obtained as a pale yellow solid (77\% yield) without further purification. ${ }^{1} \mathrm{H}$ NMR $\left(300 \mathrm{MHz}\right.$, DMSO-d $\left.{ }_{6}\right): \delta 9.57(\mathrm{~d}, J=5.4 \mathrm{~Hz}$, $1 \mathrm{H}), 9.42(\mathrm{~d}, J=8.7 \mathrm{~Hz}, 1 \mathrm{H}), 8.74(\mathrm{~d}, J=8.3 \mathrm{~Hz}, 1 \mathrm{H})$, $8.18-8.06(\mathrm{~m}, 2 \mathrm{H}), 7.81(\mathrm{t}, J=7.6 \mathrm{~Hz}, 1 \mathrm{H}), 7.70(\mathrm{dd}, J=8.3$, $5.4 \mathrm{~Hz}, 1 \mathrm{H}), 2.54(\mathrm{~s}, 6 \mathrm{H})$. Due to the low solubility of the complex, ${ }^{13} \mathrm{C}$ NMR spectrum was not possible to acquire. ${ }^{195} \mathrm{Pt}$ NMR (64.5 MHz, DMSO-d 6 ) $\delta:-3029.3$. Anal. calcd. 
for $\mathrm{C}_{11} \mathrm{H}_{13} \mathrm{Cl}_{2} \mathrm{NOPtS}$ : C, 27.92; H, 2.77; N, 2.96; S, 6.77; found: $\mathrm{C}, 27.71 ; \mathrm{H}, 2.83 ; \mathrm{N}, 2.77 ; \mathrm{S}, 6.58$.

[PtCl(8-O-quinoline)(dmso)] (2). The product was obtained following the general procedure as a yellow-orange solid (78\% yield) without further purification. MP $\left({ }^{\circ} \mathrm{C}\right)$ 197.0-198.0 (decom.). ${ }^{1} \mathrm{H}$ NMR (300 MHz, $\left.\mathrm{CD}_{2} \mathrm{Cl}_{2}\right) \delta$ $9.41(\mathrm{dd}, J=10.7,1.2 \mathrm{~Hz}, 1 \mathrm{H}), 8.38(\mathrm{dd}, J=8.4,1.1 \mathrm{~Hz}$, $1 \mathrm{H}), 7.58-7.40(\mathrm{~m}, 2 \mathrm{H}), 7.02-7.06(\mathrm{~m}, 2 \mathrm{H}), 3.61(\mathrm{~s}$, $6 \mathrm{H}) .{ }^{13} \mathrm{C}$ NMR $\left(75 \mathrm{MHz}, \mathrm{CD}_{2} \mathrm{Cl}_{2}\right) \delta 148.6,148.3,140.3$, 140.2, 131.5, 131.0, 121.7, 115.6, 114.6. 46.6. ${ }^{195} \mathrm{Pt}$ NMR (64.5 MHz, $\left.\mathrm{CD}_{2} \mathrm{Cl}_{2}\right) \delta$ : -2760.7 . HRMS $\left(\mathrm{FAB}^{+}\right)$: calcd for $\mathrm{C}_{11} \mathrm{H}_{12} \mathrm{ClNO}_{2} \mathrm{PtS}\left(\mathrm{M}^{+}\right)$: 452.9915; found: 452.9928. Anal. calcd. for $\mathrm{C}_{11} \mathrm{H}_{12} \mathrm{ClNO}_{2} \mathrm{PtS}$ : C, 29.18; H, 2.67; N, 3.09; found: C, 29.00; H, 2.67; N, 2.94 .

\section{Stability of the complexes in solution}

The ${ }^{1} \mathrm{H}$ and ${ }^{195} \mathrm{Pt}$ NMR stability studies were carried out using $0.022 \mathrm{mM}$ solution of complex $\mathbf{1}$ or complex $\mathbf{2}$ in a 3:1 mixture of DMSO- $\mathrm{d}_{6} / \mathrm{D}_{2} \mathrm{O}$. The samples were monitored by NMR at different time points.

\section{Cell line and growth conditions}

MG-63 human osteosarcoma cells (CRL1427 ${ }^{\mathrm{TM}}$ ) and L929 mouse fibroblasts (CRL 6364 $4^{\mathrm{TM}}$ ) were grown in DMEMcontaining $10 \% \mathrm{FBS}, 100 \mathrm{U} / \mathrm{mL}$ penicillin, and $100 \mu \mathrm{g} / \mathrm{mL}$ streptomycin at $37{ }^{\circ} \mathrm{C}$ in $5 \% \mathrm{CO}_{2}$ atmosphere. Cells were seeded in a $75 \mathrm{~cm}^{2}$ flask, and when $70-80 \%$ of confluence was reached, cells were subculture using $1 \mathrm{~mL}$ of TrypLE ${ }^{\mathrm{TM}}$ per $25 \mathrm{~cm}^{2}$ flask. For experiments, cells were grown in multiwell plates. When cells reached the desired confluence, the monolayers were washed with DMEM and were incubated under different conditions according to the experiments.

\section{D In vitro studies}

\section{Cell viability: crystal violet assay and MTT assay}

A mitogenic bioassay was carried out as described by Okajima et al. [23] with some modifications. Briefly, cells were grown in 48 -well plates. For experiments, $3 \times 10^{4}$ cells $/ \mathrm{mL}$ were grown for $24 \mathrm{~h}$ at $37{ }^{\circ} \mathrm{C}$. After that, the monolayers were incubated for 6 and $24 \mathrm{~h}$ with different concentrations $(10-50 \mu \mathrm{M})$ of both complexes. Then, the dye solution was discarded and the plate was washed with water and dried. The dye taken up by the cells was extracted using $0.5 \mathrm{~mL} /$ well $0.1 \mathrm{M}$ glycine/HCl buffer, $\mathrm{pH} 3.0 / 30 \%$ methanol and transferred to test tubes. After a convenient sample dilution, the absorbance was read at $540 \mathrm{~nm}$.

\section{MTT assay}

The MTT assay was performed according to Mosmann [24]. Briefly, cells were seeded in a 96-multi-well dish, allowed to attach for $24 \mathrm{~h}$, and treated with different concentrations of $\mathbf{1 , 2}$ and cisplatin at $37^{\circ} \mathrm{C}$ for $24 \mathrm{~h}$. After that, the medium was changed and the cells were incubated with $0.5 \mathrm{mg} / \mathrm{mL}$ MTT under normal culture conditions for $3 \mathrm{~h}$. Color development was measured spectrophotometrically in a Microplate Reader at $570 \mathrm{~nm}$ after cell lysis in DMSO $(100 \mu \mathrm{L} /$ well).

\section{Single-cell gel electrophoresis (SCGE) assay}

For detection of DNA strand breaks, the single-cell gel electrophoresis ('comet') assay was used in the alkaline version, based on the method of Singh et al., with minor modifications [25]. Analysis of the slides was performed in an Olympus BX50 fluorescence microscope. Cellular images were acquired with the Leica IM50 Image Manager (Imagic Bildverarbeitung AG). A total of 50 randomly captured cells per experimental point of each experiment were used to determine the tail moment (product of tail length by tail DNA percentage) using a free comet scoring software (Comet Score version 1.5).

\section{DNA cleavage assay}

Cleavage of plasmid DNA (pA1) by the three complexes (1, $\mathbf{2}$, and cisplatin) was examined by agarose gel electrophoresis under inorganic (phosphate buffer) and organic (MOPS) media at physiological $\mathrm{pH}$ according to a previous report. DNA cleavage activity of the complexes was evaluated by the amount of supercoiled plasmid DNA ( $\mathrm{Sc}$ ) converted into nicked circular DNA (Nck) and linear DNA (Lin). $1 \%$ agarose gel in $0.5 \times$ TBE was prepared as described elsewhere [26]. Peak areas for the Sc form were always corrected by factor 1.47 to account for its weak binding capacity to ethidium bromide [27].

\section{Determination of reactive oxygen species (ROS) production}

Oxidative stress in osteoblasts was evaluated by the measurement of intracellular production of reactive oxygen species (ROS) after incubation of the cell monolayers with different concentrations of the complex during $6 \mathrm{~h}$ at $37{ }^{\circ} \mathrm{C}$. ROS generation was determined by the oxidation of DHR123 to rhodamine by Fluorescence spectroscopy as we have previously described by León and co-workers [28]. As a positive control, we use $\mathrm{H}_{2} \mathrm{O}_{2}$ ( $20 \mathrm{~min}, 0.75 \mathrm{mM}$ ). 
Measurement of the exposure of phosphatidyl serine (PS) by Annexin V-FITC/PI Staining

Cells in the early and late stages of apoptosis were detected with Annexin V-FITC and Propidium Iodide (PI) staining. Cells were treated with 10 and $50 \mu \mathrm{M}$ of compound 2 and incubated for $6 \mathrm{~h}$ prior to analysis. Cells were analyzed using a flow cytometer (BD FACs Calibur ${ }^{\mathrm{TM}}$ ) and FlowJo 7.6 software. For each analysis, 10,000 counts, gated on a FSC vs. SSC dot plot, were recorded.

\section{Mitochondrial membrane potential (MMP)}

The mitochondrial permeability detection Kit (MTt-E-j, Biomol International) was used to analyze the mitochondrial membrane potential according to the manufacturer's instructions.

For the control condition, we are using carbonyl cyanide m-chlorophenylhydrazone (CCCP, $50 \mu \mathrm{M})$.

\section{D In vitro studies}

\section{Multicellular spheroid formation}

The development of multicellular spheroids was achieved by the hanging drop technique with minor modifications [29]. For pharmacologic experiments, multicellular spheroids were treated with: $1 \%$ dimethyl sulfoxide in DMEM (basal) and 5-150 $\mu \mathrm{M}$ of compound 2 and cisplatin for $24 \mathrm{~h}$. After that, the evaluation of damage in cell viability of spheroids was achieved by resazurin reduction assay.

\section{In vivo studies}

\section{Tumor implantation, treatment, and evaluation}

Xenograft tumors were established in 6-week-old male nude (N:NIH(S)-Fox $\boldsymbol{I}^{\boldsymbol{n} \boldsymbol{u}}$ ) mice.

Mice were kept under specific pathogen-free (SPF) conditions. Mice were inoculated subcutaneously (s. c.) into the right flank with $2 \times 10^{6}$ human osteosarcoma MG-63 cells. Tumor size was assessed using a caliper and approximate tumor burden $\left(\mathrm{mm}^{3}\right)$ was calculated as length $\times$ width ${ }^{2} / 2\left(V=l w^{2} / 2\right)$, where length and width are the longest and shortest axes in millimeters [30].

For pharmacologic experiments, mice were treated when the xenograft tumors reached $400 \mathrm{~mm}^{3}$. Mice received an injection of PEG400 in phosphate-buffered saline (5\% $n=5$, vehicle control mice), complex 2 (6 mg/
$\mathrm{Kg}, n=5$ treated mice $)$, and cisplatin $(6 \mathrm{mg} / \mathrm{Kg}, n=5$ treated mice): via intraperitoneal twice a week for 30 days.

\section{Histopathological studies and biochemical parameters}

Animals were sacrificed, and liver, kidney, and tumor were dissected out. These organs were fixed and then dehydrated and embedded in paraffin.

The slides were stained with hematoxylin-eosin, cleared with xylene for half an hour and mounted with Canada balsam.

Blood collections and biochemical analysis [uremia, creatinine, aspartate aminotransferase (GOT), and alanine aminotransferase (GPT)]

To analyze whether there were any biochemical changes in the kidney and liver of the animals, serum uremia, creatinine, GOT, and GPT enzymatic activity levels were quantified. A total of $1000 \mu \mathrm{L}$ of blood were collected via cardiac puncture. Blood samples were centrifuged at $1000 \mathrm{~g}$ for $10 \mathrm{~min}$ to separate the serum and stored. Enzymatic activity measurements were performed using biochemical diagnostic kits from Wiener Lab.

\section{Statistical analysis}

Statistical analyses were performed using STATGRAPHICS Centurion XVI.I software. At least three independent experiments were performed for each experimental condition in all the biological assays. The results are expressed as the mean \pm the standard error of the mean (SEM). Statistical differences were analyzed using the analysis of variance method (ANOVA) followed by the test of least significant difference (Fisher).

\section{Results}

\section{Synthesis of platinum complexes ( 1 and 2 ) and stability studies}

Platinum compounds were synthesized according to our previous results [16]. The structures of these compounds have been proposed on the basis of elemental analysis, NMR, and IR spectroscopy [16].

In the previous studies, we reported the lower stability in solution of monodentate-quinoline-platinum(II) complexes compared to chelate complexes. These stability studies were carried out in saline solution and analyzed by reversed-phase HPLC. We now performed the stability of complexes 1 and 2 by ${ }^{1} \mathrm{H}$ and ${ }^{195} \mathrm{Pt}$ NMR (Fig. 1) to identify the different species in solution that could be related to the different activity 
A

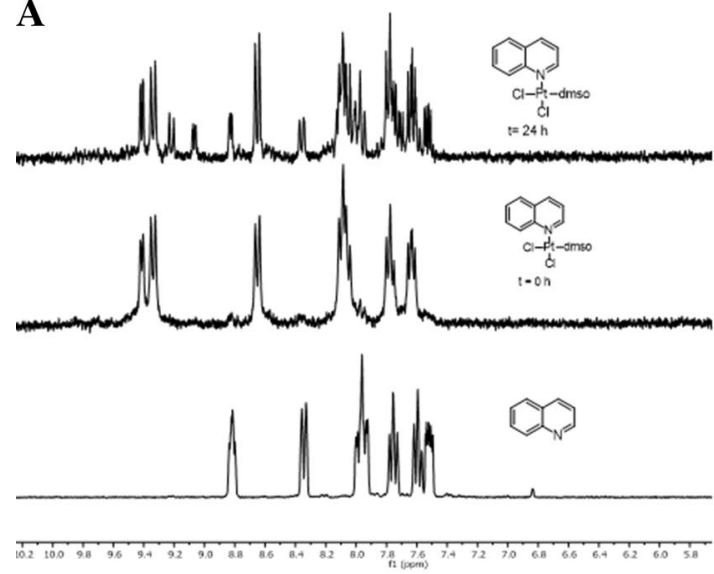

B
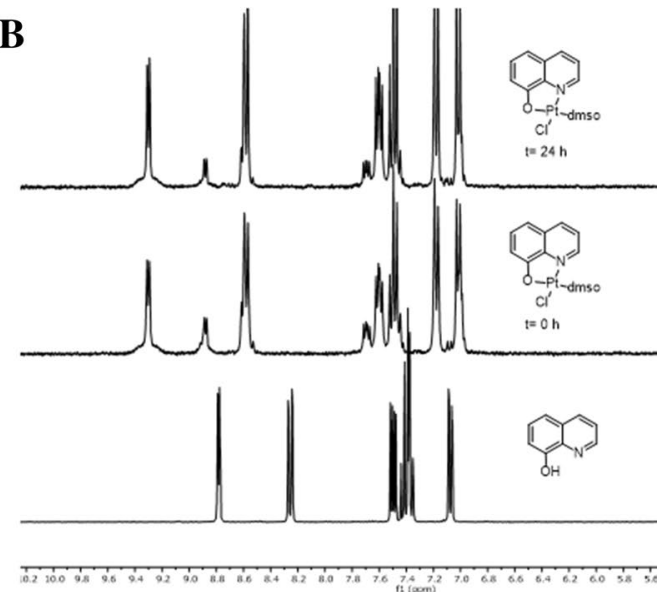

Fig. 1 The ${ }^{1} \mathrm{H}$ and ${ }^{195} \mathrm{Pt}$ NMR stability studies were carried out using solution of complex 1 or complex $\mathbf{2}$ in DMSO-d $\mathrm{d}_{6} / \mathrm{D}_{2} \mathrm{O}$. The samples were monitored by NMR at different time points

observed for both complexes. The ${ }^{1} \mathrm{H}$ NMR spectra of chelate complex 2 showed the high stability of the complex in solution along the time. Although a small amount $(<15 \%)$ of a different species was detected at the initial time $(t=0 \mathrm{~h})$, these species remained unaltered along the time. By contrast, the NMR studies of monodentate complex 1 showed its low stability in solution. After $24 \mathrm{~h}$, different species were detected by ${ }^{1} \mathrm{H}$ NMR. Besides complex 1, the chemical shifts of the free quinoline ligand were also identified. In addition, a new signal at $-3456.8 \mathrm{ppm}$ appears in the ${ }^{195} \mathrm{Pt}$ NMR spectrum. This signal corresponds with the reported chemical shift of $c i s-\mathrm{PtCl}_{2}(\mathrm{dmso})_{2}$ [31], which is formed by quinoline-DMSO exchange reaction in complex $\mathbf{1}$.

\section{D In vitro studies}

\section{Cytotoxicity studies}

To get a deeper insight into the antiproliferative effects of these quinolone-platinum compounds, the cytotoxicity of complexes 1 and 2 was investigated (Fig. 2). After 6 h, complex 2 reduced cell viability in the range of $10-50 \mu \mathrm{M}$, while compound 1 did not show any effect $(p<0.01$, Fig. 2$)$. After $24 \mathrm{~h}$, compound 2 induced a decrease in cell viability at the concentration as low as $10 \mu \mathrm{M}$, whereas, for 1 , this effect is observed at $25 \mu \mathrm{M}$. The data presented herein show some cytotoxic effects of both compounds in a concentrationand time-dependent manner with statistically significant differences vs. control (without complex addition) (Fig. 2a, $\mathrm{b}, p<0.01)$. Besides, the alteration in the energetic cell metabolism was determined by the MTT assay. After $24 \mathrm{~h}$, both compounds caused an inhibitory effect on cell viability in the range of 5-100 $\mu \mathrm{M}$ and 50-100 $\mu \mathrm{M}$, respectively. (Fig. 2c, $p<0.01$ ).
To assess the antitumor effectiveness of both platinum compounds, we compared their effects with the reference metallodrug (cisplatin) in MG-63 cells. Interestingly, these results show that compound 2 seems to have a more pronounced antitumor effect than cisplatin on MG-63 osteosarcoma cells $\left(\mathrm{IC}_{50} 4 \mu \mathrm{M}\right.$ vs. $\left.39 \mu \mathrm{M}\right)$, with $\mathrm{IC}_{50}$ value tenfold lower than cisplatin.

The results obtained suggest that the dramatic effect on the anticancer activity against osteosarcoma is probably due to the difference in ligand structure, i.e., monodentate quinoline ligand in 1 complex and the hydroxyquinolate $\mathrm{N}, \mathrm{O}-$ chelate ligand in 2 . The chelate compound seems to be considerably more active in comparison to the non-chelate complex. Altogether, the NMR data seem to indicate that the low stability of the monocoordinate complex 1 is due to its high reactivity with the subsequent release of the quinoline ligand. This high reactivity and low stability of quinoline complex (1) would explain the lower antitumor activity of complex 1 compared to complex 2 (see Fig. 1).

On the other hand, to understand the specific potential of compound $\mathbf{2}$ and to address its selectivity for cancer cells, we investigated their effect on the cell viability of mousederived fibroblast (L929 cells) and we compared their effects by calculating the selectivity index (SI).

Table 1 shows that compound has a great selectivity on MG-63 compared to cisplatin. The SI value of compound 2 is four times higher than SI value of cisplatin, suggesting that the complex $\mathbf{2}$ has a higher selectivity than cisplatin.

\section{Genotoxicity studies}

The genotoxic effects and nuclease activity of complexes 1 and 2 were investigated through the induction of DNA damage by the Comet assay (SCGE) and the DNA plasmid cleavage. 

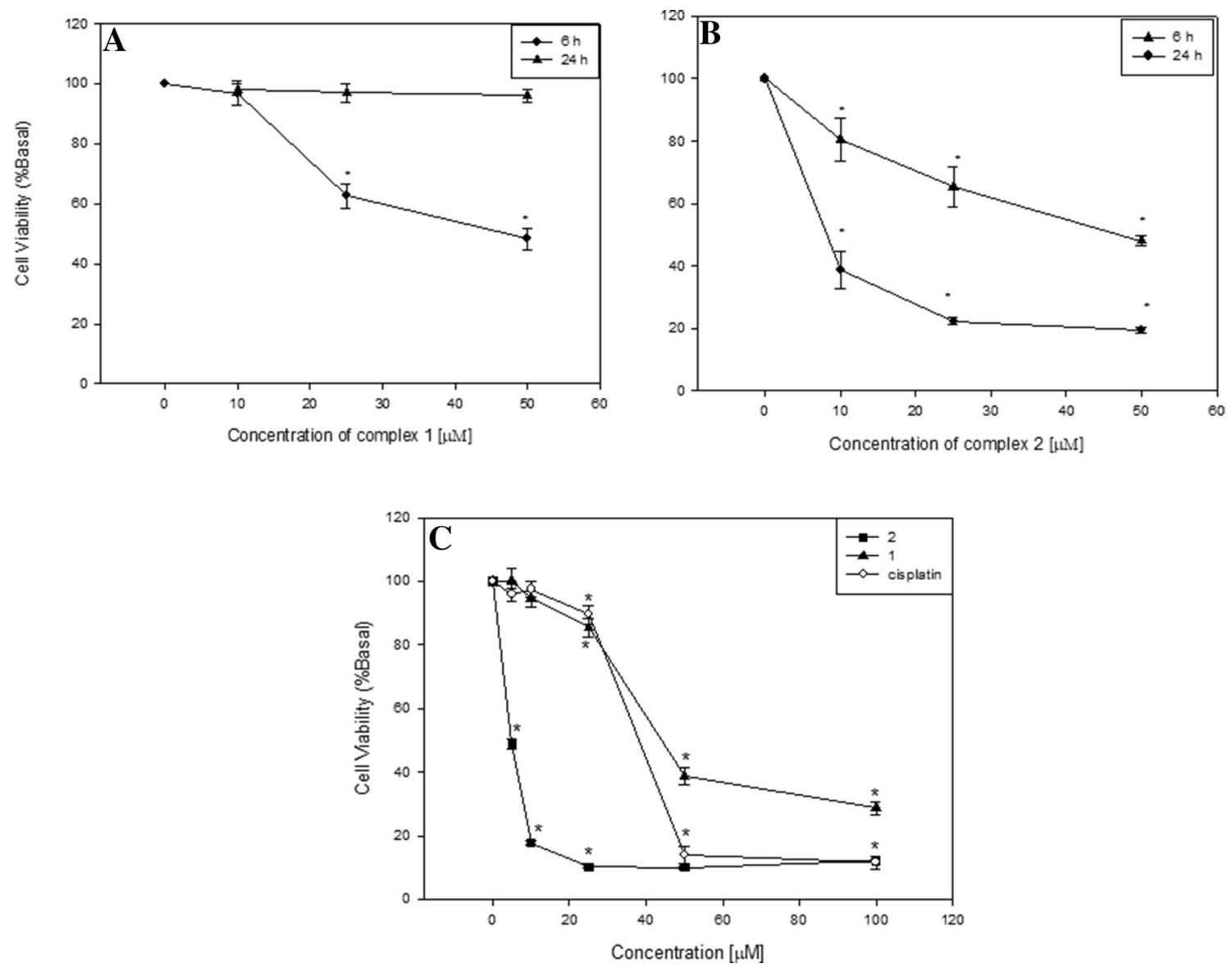

Fig. 2 Effects of complex 1 (a) and 2 (b) on MG-63 human osteosarcoma cell viability using crystal violet method. Effects of complex 1, 2, and cisplatin on MG-63 human osteosarcoma cell viability using MTT assay (c). The results are expressed as the percentage of the

Table $1 \mathrm{IC}_{50}(\mu \mathrm{M})$ and $\mathrm{SI}$ values of complex 2 and cisplatin on L929 and MG-63 cells of after $24 \mathrm{~h}$

As it is shown in Fig. 3a, complexes 1, 2, and cisplatin produced a significant genotoxic effect on MG-63 cells from 1 to $2.5 \mu \mathrm{M}(p<0.01)$. In this order, the compound 2 showed stronger genotoxic effects than compound 1 and cisplatin at $1 \mu \mathrm{M}$. At $2.5 \mu \mathrm{M}$ the genotoxic effect is less pronounced. The effect that the damage in DNA decreases as the complex concentration increases may be due to overt cytotoxicity exerted on this cell line.

Considering the results of both platinum compounds in DNA cleavage as a whole, we decided to investigate the interaction of the complexes with an in vitro DNA plasmid model (pDNA). The nuclease activity of compounds 1 and 2 under phosphate buffer is shown in Fig. 3b. As it can be seen, complex 1 is less active than 2 in the presence of basal level and represent the mean \pm the standard error of the mean (SEM) $(n=18)$. Asterisk represent significant difference in comparison with the basal level $(p<0.01)$.

oxone. In this condition, a double-strand cleavage was also observed, to a greater extent for compound 2 (lane 10) than for compound 1 (lane 6). Moreover, no significant changes were observed in the presence of mercaptopropionic acid (MPA) (lanes 7 and 11). Interestingly, cisplatin did not cause any effect towards DNA cleavage (lanes 4 and 12).

Altogether, these results suggest that complexes 1 and 2 induced single- and double-strand DNA breaks in MG-63 cells, leading to a positive result in the Comet assay, which is significantly detected at lower concentrations, mainly for complex 2. Besides, both compounds are active toward pA1 plasmid DNA model which suggests a possible nuclease activity.

\section{Mechanism of action}

The putative cell death mechanisms triggered by the most active platinum complex (2) were investigated through the determination of the oxidative stress and an exhaustive study of apoptosis. 


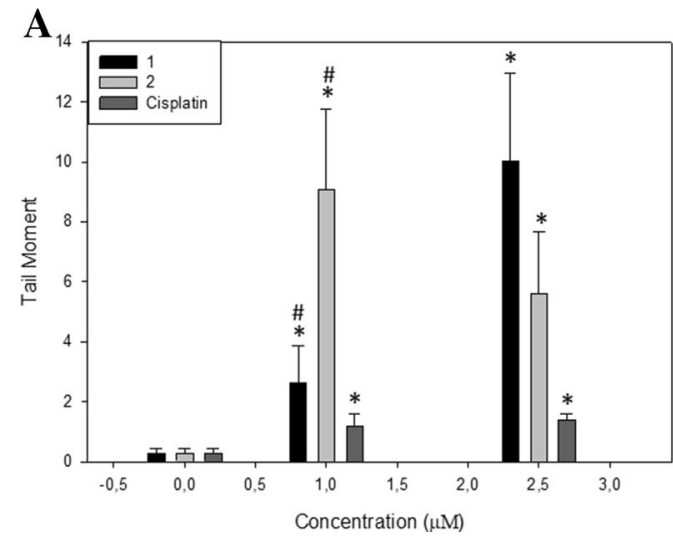

Fig. 3 Genotoxicity studies of both complexes toward MG-63 tumor cells and plasmid DNA. a Comet assay: single-cell gel electrophoresis. Induction of DNA damage by complex 1, 2, and cisplatin in the MG-63 human osteosarcoma cell line. DNA damage was evaluated by the tail moment. The results are expressed as the mean \pm SEM $(n=150)$. $* p<0.01$. b DNA cleavage activity of complex 1 (lanes

\section{Oxidative stress}

Oxidative stress has been reported as one of the main factors that trigger the deleterious actions of metal-based drugs [32-34].

Incubation of osteosarcoma cells with different concentrations of 2 caused an increment on the induction of ROS. The compound increased ROS production after $6 \mathrm{~h}$ in a dose-manner response at $25 \mu \mathrm{M}(160 \%), 50 \mu \mathrm{M}(200 \%)$, and $100 \mu \mathrm{M}(411 \%)(p<0.01)$. Besides, cisplatin only induced ROS production at $100 \mu \mathrm{M}(427 \%)$, whilst, at 25 and $50 \mu \mathrm{M}$, the compound did not increase the ROS levels $(p<0.01)$. In addition, $\mathrm{H}_{2} \mathrm{O}_{2}$ (positive control) increased the levels of ROS on 35.

The increase in ROS levels has been associated with cell death or membrane injury. Overall, it can be assumed that the free radicals decrease the concentration of important cellular compounds and impair the antioxidant system making cells more vulnerable to oxidative damage.

\section{Apoptosis study}

Different scientific reports have shown that high levels of ROS can induce apoptosis by activating the mitochondrialmediated apoptotic pathway $[35,36]$.

To evaluate the effect of complex concentration on apoptosis induction, we used two concentrations (10 and $50 \mu \mathrm{M})$ of 2 . Figure 4 displays the flow cytometry results of the apoptotic process and the quantification of early and late stages of apoptosis in basal condition and in the presence of 2 .

Figure 4 shows that, after $6 \mathrm{~h}$ of incubation, the control cultures showed 3\% of early apoptotic cells Annexin

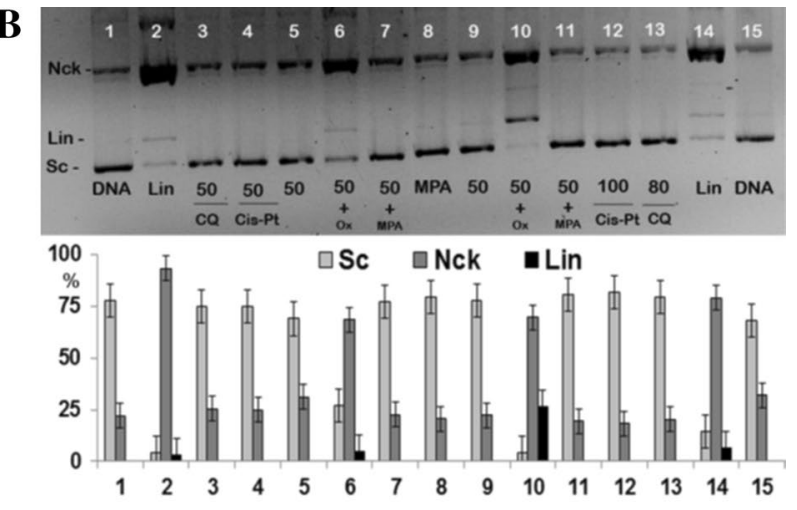

5-7) and CR-175 (lanes 9-11) prepared in 0.5\% DMSO at $50 \mu \mathrm{M}$ in the presence of activating agents (oxone and MPA) under $10 \mathrm{mM}$ PBS buffer. Upper part: visualized DNA bands in 1\% agarose gel. Lower part: a chart column with the calculated percentage of DNA bands corresponding to each lane in the gel

$\mathrm{V}(+)$ and $3 \%$ of late apoptotic cells Annexin $\mathrm{V}(+) / \mathrm{PI}(+)$. These results changed with 10 and $50 \mu \mathrm{M}$ of 2 , showing an increase in the early/late apoptotic cellular fractions. At $10 \mu \mathrm{M}$, complex 2 produced ca. $9 \%$ of early apoptotic cells [Annexin $\mathrm{V}(+)$ ] and $16 \%$ of late apoptotic cells [Annexin $\mathrm{V}(+) / \mathrm{PI}(+)]$, while, at $50 \mu \mathrm{M}$, the late apoptotic fraction increased to $41 \%(p<0.01)$. As it can be seen, the percentages of apoptotic and apoptotic/necrotic cells increased with the complex concentration. These results are in accordance with the cell viability assays, confirming that the antiproliferative action of $\mathbf{2}$ is dependent on the compound concentration in the MG-63 cells. On the other hand, Fig. SM1 showed that cisplatin did not induce apoptosis effects after $6 \mathrm{~h}$ of incubation.

Mitochondria are one of the most important organelles that can regulate cellular apoptosis [37]. The mitochondrial transmembrane potential (MMP) preserves the integrity and functions of the mitochondria. Dissipation of the MMP can lead the cells to apoptosis or necrosis [38]. To elucidate if deleterious effects of the platinum derivative $\mathbf{2}$ in human osteosarcoma cells included the alterations of mitochondrial functions, we evaluated the MMP in MG-63 cells under control conditions and in the presence of the lethal concentration of $2(50 \mu \mathrm{M})$. The changes in MMP were measured by flow cytometry using the probe JC1.

As it can be seen a significant percentage of cells displayed reduced mitochondrial membrane potential (higher green fluorescence and lower red fluorescence, Figure SM1), suggesting a role of the mitochondrial pathway in two induced osteosarcoma apoptosis. These results are in agreement with the oxidative stress and PS externalization assays, suggesting that the main mechanisms of antitumor actions of the compound include ROS production and apoptosis. 

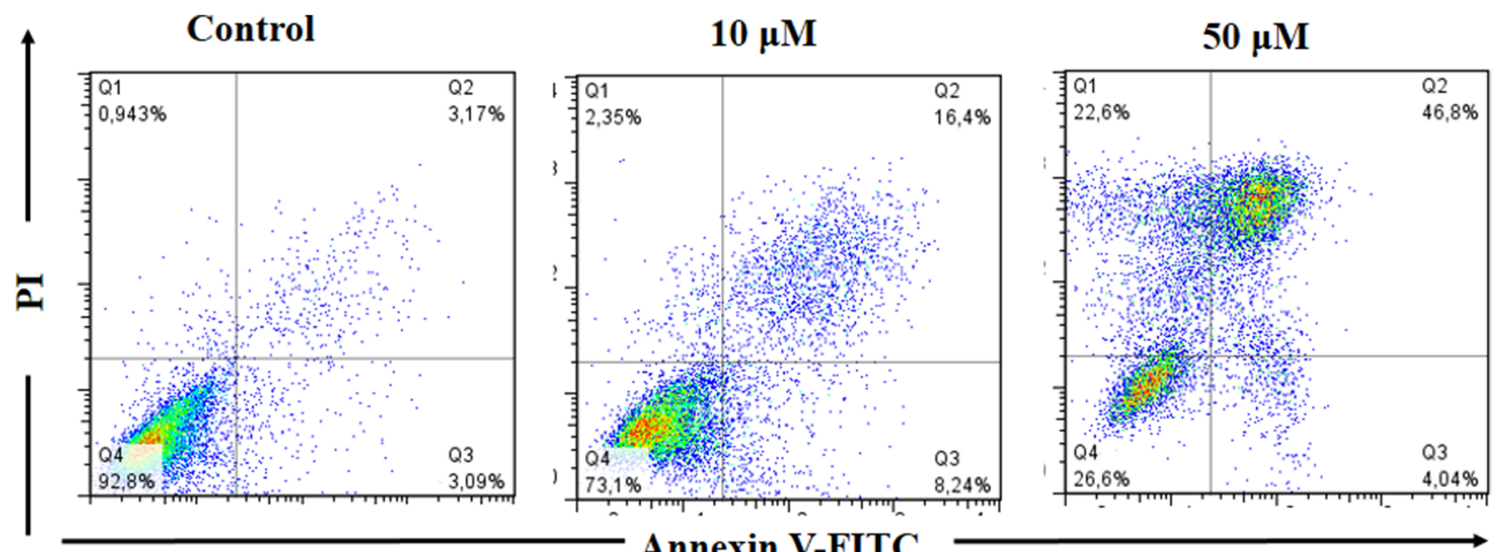

Annexin V-FITC

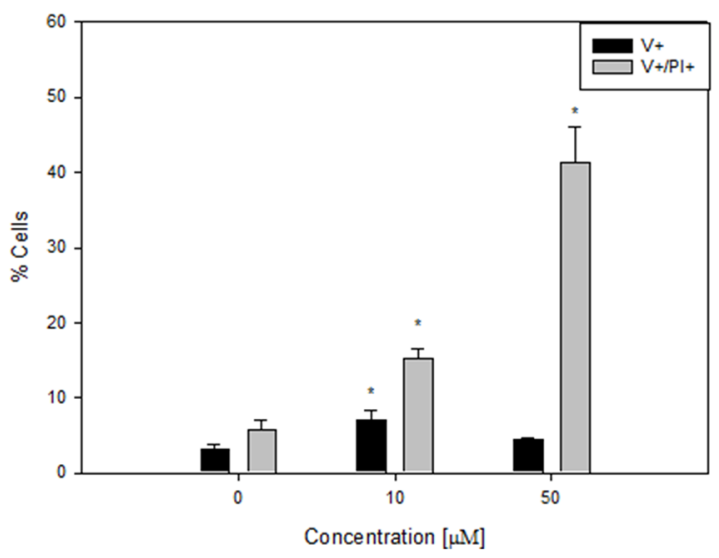

Fig. 4 Effect of complex 2 on the externalization of PS by flow cytometry in MG-63 cells. Cells were incubated with 10 and $50 \mu \mathrm{M}$ of complex 2 during $6 \mathrm{~h}$. Graphical bars show the percentage of

\section{D In vitro studies}

\section{Effects of complex 2 and cisplatin on the cell viability of MG-63 multicellular spheroids}

Anticancer efficacy of platinum compounds was assessed by means of using resazurin reduction assay which is a useful marker of cell viability in multicellular spheroids [39, 40].

The data presented herein show a cytotoxic effect of complex 2 and cisplatin with statistically significant differences vs. the control (basal condition) $(p<0.01)$.

Figure 5 shows the effects of compound 2 and cisplatin on cell viability in MG-63 multicellular spheroids. At lower concentration $(5$ and $10 \mu \mathrm{M})$, only compound 2 impaired the cell viability of the multicellular spheroids showing a reduction of the $20 \%$ of the resazurin activity. Nevertheless, from 25 to $150 \mu \mathrm{M}$, cisplatin decreases drastically the cell viability of multicellular showing stronger anticancer activity than compound 2 .

These results are in contrast to the $2 \mathrm{D}$ cell viability results in which complex 2 shows higher antitumor activity than cisplatin, suggesting that some aspects such us hypoxic
Annexin $\mathrm{V}(+)$ and Annexin $\mathrm{V}(+) / \mathrm{PI}(+)$ cells. Results are expressed as the mean \pm SEM, $n=9$, *significant differences vs. control $(p<0.01)$

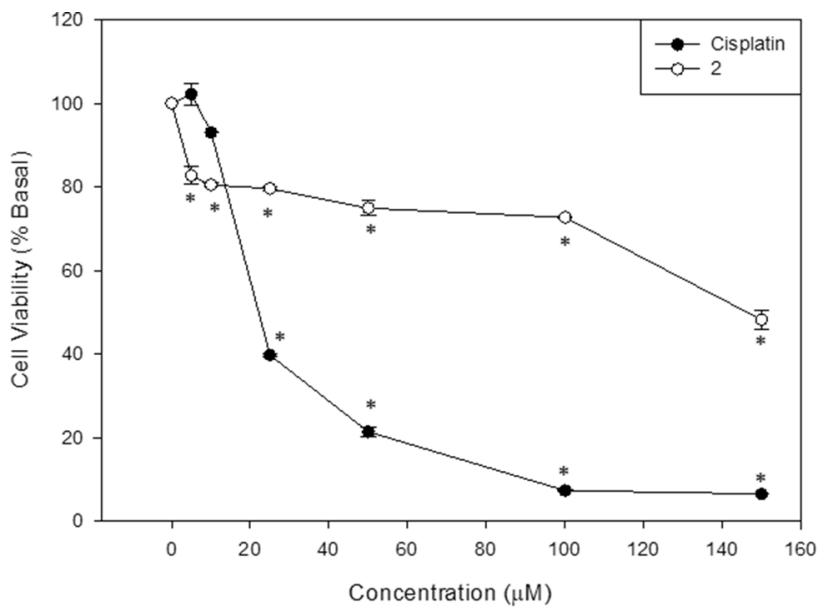

Fig. 5 Effects of complex 2 and cisplatin on cell viability of MG-63 multicellular spheroids. For cell viability assay, one spheroid was incubated in Dulbecco's modified Eagle's medium (DMEM) alone (basal) or with $5-150 \mu \mathrm{M}$ of complex 2 and cisplatin at $37{ }^{\circ} \mathrm{C}$ for $24 \mathrm{~h}$. Then, the resazurin activity was measured as cell viability biomarker. The results are expressed as the percentage of the basal level and represent the mean \pm the standard error of the mean (SEM) $(n=18)$. *In comparison to the basal level $(p<0.01)$ 
conditions, redox potential, cell uptake, and bioavailability are key to define the anticancer activity of antitumor drugs [41].

\section{In vivo studies}

\section{Compound 2 antitumor efficacy evaluation in athymic nude mice N:NIH(S) Fox1nu bearing human osteosarcoma tumor derived from MG-63 cell line}

After estimations of the in vitro antitumor activity of both platinum complexes 1 and 2 (see above), we decided to assess in vivo anticancer activity of the most active compound.

In Fig. 6a, in vivo antitumor effects of compound 2 in osteosarcoma mice model can be seen. Statistically significant differences could be observed in tumor volumes after the 7th day of treatment, where treated tumors were smaller than controls $(* p<0.01)$. In this sense, the values of tumor volume $\left(\mathrm{mm}^{3}\right)$ were $543 \pm 38,455 \pm 24$ for control and treatment, respectively. After 14 days of treatment, it was observed that compound 2 continued tumor reduction compared to the control conditions, obtaining values of $622 \pm 56$ and $418 \pm 39 \mathrm{~mm}^{3}$ for control and treatments, respectively $\left({ }^{*} p<0.01\right)$. Tumor size was determined for the last time 2 days after finishing treatment (day 32th). As it can be seen, the difference among both groups remained to be statistically significant, with values of $989 \pm 68$ and $650 \pm 53$, for control and treatment, respectively. Besides, complex 2 blocked bone tumor growth in the xenograft model without inducing cytotoxicity and several side effects, as shown in Fig. 6 b.

In addition, to determine the antitumor effectiveness of compound $\mathbf{2}$, we compared its effects with those of the

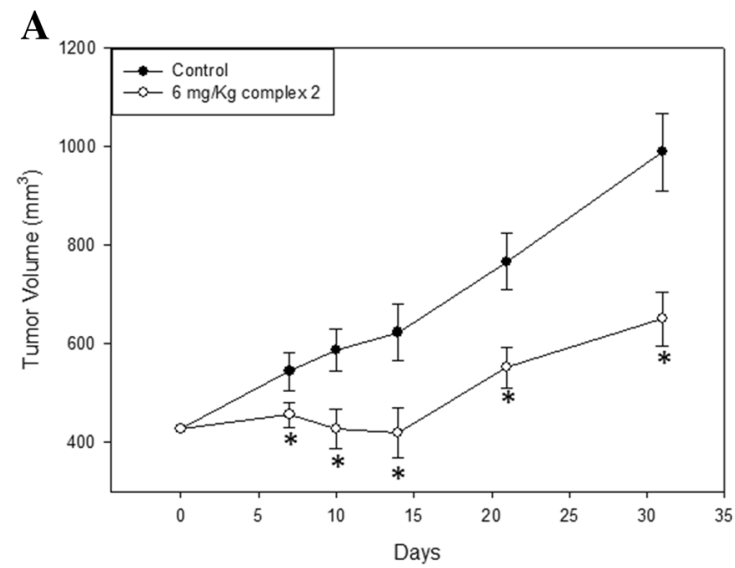

Fig. 6 a In vivo antitumor effects of compound 2. MG-63 cells were inoculated subcutaneously into the right flank of nude mice and allowed to form tumors (Control, compound $2(6 \mathrm{mg} / \mathrm{Kg})$. Tumor volume was measured at the indicated time points after the onset of treatment. In relative volume ( $V$ volume, $V_{0}$ initial volume). All reference metallodrug (cisplatin) in xenograft osteosarcoma in vivo model. Figure SM2 shows the improvement of life span of xenograft-bearing mice treated compound $2(6 \mathrm{mg} /$ $\mathrm{Kg})$ in comparison with cisplatin $(6 \mathrm{mg} / \mathrm{Kg})$. After treatment of cisplatin, the animals died on day 10,14 , and 16 . It is worth mentioning that, under control and compound $\mathbf{2}$ conditions, animals were not affected. On the 32th day, the control and compound $\mathbf{2}$ treatment groups were sacrificed in agreement with the ethical statement endpoint. These results showed that only cisplatin-treated mice die suggesting the importance role of toxic side effects of cisplatin of life span of animals. In agreement with our results, many scientific reports described the toxicity exerted of cisplatin in different tissues such us kidney, stomach, etc. [42, 43].

Mice in the control experiments also have tumors, but they do not die as is the case with mice treated with complex 2 (Figure SM2). Only cisplatin-treated mice die, probably due to the toxic side effects. The authors should add a comment on that already in the results.

\section{Histopathological examination and biochemical parameters}

Osteosarcoma is a sarcomatous tissue with abnormal osteocytes cells. These cells produce an osteoid eosinophilc substance (immature bone trabeculae), which is characteristic of this kind of tumor. The osteocytes were characterized by an intense basophiles cytoplasm, and an atypical and irregular nucleus with anisocytosis, pyknosis, and karyorrhexis. These tumors presented a high mitotic index in the peripheral zone and a big coagulative necrotic area in the middle (see Fig. SM3a). Tumor coagulative necrosis is due to protein denaturation because of the rapid tumor growth or

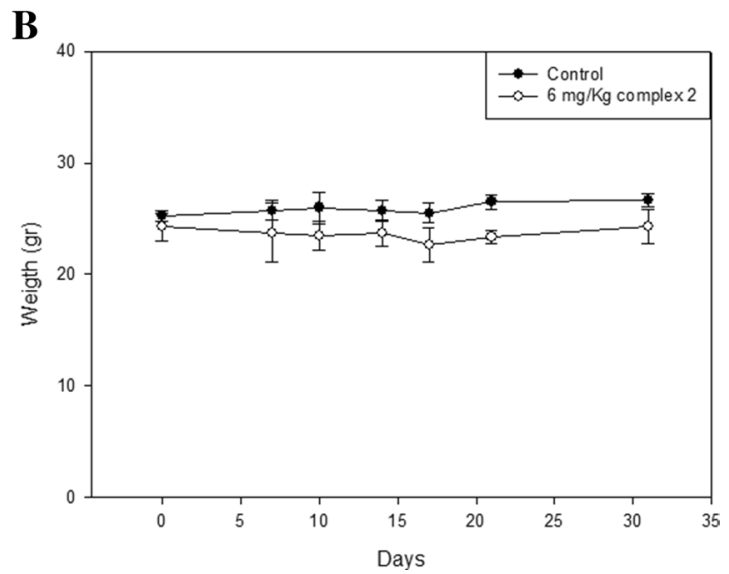

data are presented as mean \pm SEM for 5 mice/group. ${ }^{*} p<0.01$ with reference to basal, ${ }^{\#} p<0.01$ between treatments. b Animal weight changes. Weight was measured every 3 days. All data are presented as mean \pm SEM for 5 mice/group. $* p<0.01$ with reference to basal, ${ }^{\#} p<0.01$ between treatments 
as a consequence of ischemia (Fig. SM3b). After treatment with the platinum complex, more space between the cells and an increase in the fibrous tissue as a consequence of the necrosis process was found (Fig. SM3c). The mitotic index was low, and the apoptotic cells were observed in larger quantities than in the control group (see Fig. SM3d). The tumor cell nuclei showed karyorrhexis. This process occurs because of nuclear disintegration and as a consequence of the chromatin fragmentation.

The microphotograph of the liver section of the control group showed normal architecture and appearance (Fig. SM4a). As it can be seen in Fig. SM4a and SM4b, there was not steatosis. After treatment, the architecture of the liver remained normal, but it could be seen the presence of around $10 \%$ of microvacuolar steatosis (Fig. SM4d). This process is very common in chemotherapy, but it is slight and regenerative. There were some lymphoid cells and higher quantities of Kupffer cells in the sinusoids (Fig. SM4e). In conclusion, platinum complex $\mathbf{2}$ is slightly hepatotoxic, but this process is slight and reversible. On the other hand, Fig. $\mathrm{SM} 4 \mathrm{c}$ and $\mathrm{f}$ shows that no changes were observed between control and treatment samples on the kidney's architecture. In this sense, the number of mesangial cells was the same, and there was no fibrous tissue.

On the other hand, quantification of enzymatic activity levels of GOT and GPT is important in the diagnosis of heart and liver damage. Table 2 shows that the values of uremia, creatinine, GPT, and GOT did not suffer significant modifications comparing control and treatment conditions. These results are in agreement with the histopathology studies (see Figs. SM3/SM4), and this confirms that no change in kidney and liver toxicity occurred in nude mice during the treatment.

\section{Discussion}

Quinolines are a family of compounds with multiple bioactivities [13, 14]. In particular, 8-hydroxyquinoline (8HQ) possesses potent coordinating ability and good metal recognition properties, which means that it is widely used for metal chelation. In fact, pharmacological actions of these compounds are more effective than those with free ligands,

Table 2 Effect of compound 2 on serum GPT, GOT activities, and uremia, and creatinine levels in control and treatment groups in N:NIH(S) Foxl ${ }^{n u}$ mice

\begin{tabular}{llllr}
\hline & $\begin{array}{l}\text { Uremia }(\mathrm{mg} / \\
\mathrm{dl})\end{array}$ & $\begin{array}{l}\text { Creatinine } \\
(\mathrm{mg} / \mathrm{dl})\end{array}$ & GPT (U/l) & GOT (U/l) \\
\hline Control & $63.5 \pm 0.41$ & $0.55 \pm 0.01$ & $38.6 \pm 9$ & $92.5 \pm 15.2$ \\
Treatment & $66 \pm 6.5$ & $0.51 \pm 0.04$ & $60.3 \pm 8$ & $134 \pm 22.3$ \\
\hline
\end{tabular}

meaning that the anticancer properties of quinolines are enhanced by complexation with metal ions [44].

In the last years, there has been increasing interest in the synthesis of new platinum derivatives with enhanced anticancer properties and minor side effects [45, 46]. In this sense, platinum-based complexes are extensively used in the treatment of pediatric tumors like neuroblastoma, retinoblastoma, and osteosarcoma [47].

As part of a research project, we have addressed the investigation of the anticancer effects of two platinum(II) complexes with quinolines derivatives (compounds 1 and 2 ) against $2 D$, and $3 D$ human osteosarcoma cells. The results in MG-63 cell monolayers showed that compound 1 impaired cell viability in a dose-response manner from 50 to $100 \mu \mathrm{M}$, whilst the compound 2 reduced the cell viability from $10 \mu \mathrm{M}$. The antitumor activity of compound 2 was higher than compound $1\left(\mathrm{IC}_{50} 1=46 \mu \mathrm{M}, \mathrm{IC}_{50} 2=4 \mu \mathrm{M}\right)$, and exerted the antitumor actions in 2D inducing apoptosis (MMP dissipation and PS externalization) and ROS generation. Moreover, it is important to highlight that the observed increase in ROS levels is directly due to the action of compound 2 that increased ROS induction and convey the cells to apoptosis. In this sense, cisplatin also induces the formation of reactive oxygen species that can trigger cell death [48]. The antitumor activity of compound 2 is very important showing greater therapeutically effects of complex 2 compared to platinum(II)-bisphosphonates' compounds against bone cancer cells [10]. Besides, we investigated the effect of compound 2 and cisplatin on the cell viability of mouse-derived fibroblast (L929 cells) and we compared their effects by calculating the selectivity index (SI). The results showed that compound 2 has a great selectivity on MG-63 compared to cisplatin, indicating that the SI value of compound 2 is four times higher than the SI value of cisplatin.

On 3D spheroids cell systems, the compound $\mathbf{2}$ decreased cell viability at lower concentration $(5$ and $10 \mu \mathrm{M})$, but, when increased the concentration, cisplatin decreases drastically the cell viability of multicellular showing higher antitumor activity than compound 2 . These results are in contrast to the monolayers (2D) cell viability results, suggesting that redox potential, cell uptake, and bioavailability are crucial to define the anticancer activity of these kinds of compounds. Nevertheless, these results are very important, because the complex 2 induced cytotoxicity using pharmacological appropriate concentration against human osteosarcoma cells in 2D and 3D models with very interesting effects. In this order, a scientific report had previously demonstrated that osteosarcoma cell spheres displayed resistance to cisplatin and doxorubicin treatments [49]. Besides, SchreiberBrynzak et al. [41] published the effects of several clinical reference metal-based anticancer drugs, against 2D and 3D colon and ovarian cancer models. 
The advantages of 3D spheroid-based experiments in comparison to 2D models underline the necessity of using different experimental models for reliable preclinical investigations to assess and better predict the antitumor potential of novel metal-based drugs. In this way, animal models of several types of cancers have evolved in attempts to depict the complexity of this disease [50].

Our results show that compound 2 reduced tumor growth in the nude mice without inducing side effects (measured by the loss of body weight, blood biomarkers, and histopathological analysis). These results demonstrate that complex 2 caused a desired antitumor effect, because it reduced tumor volume without affecting the animals' health. In this sense, in vivo effects of compound 2 on the osteosarcoma xenograft mice model are reported herein for the first time, and it is relevant for the in vivo effects of other platinum-based drugs on xenograft osteosarcoma models [11].

\section{Conclusion}

In the present study, we have demonstrated the potential use of hydroxyquinoline-platinum(II) compounds as anticancer agents against human bone cancer. To do so, 2D (monolayer) and 3D multiple cell tumor spheroids (MCTS) models of MG-63 human osteosarcoma cell line was used to characterize the ability of two platinum(II) compounds with the quinoline ligands.

These compounds were able to block human osteosarcoma growth in cells in vitro (2D) inducing ROS, DNA damage, and programmed cell death. Besides, based on 3D in vitro evidence, compound 2 reduced the viability and altered the shape of the MCTS model showing a greater anticancer activity than cisplatin. Moreover, when complex 2 was tested in vivo, important anticancer activity was observed during the treatment. The pharmacological effects were determined through a significant suppression of bone tumor growth along 30 days of treatment.

These results demonstrate the anticancer efficacy of hydroxyquinoline-platinum compound, allowing them to be placed within platinum antitumor drugs.

Acknowledgements SBE and IEL are members of the Research Carrer, CONICET, Argentina. JFCV and MCR have a fellowship from CONICET and ANPCyT, Argentina, respectively. We also gratefully acknowledge to Dra Ortiz Mayor from Hospital Padilla, Tucuman, Argentina, to help with the Histopathology studies. Moreover, the authors would like to thank MC. Bernal for her careful revision of the manuscript.

Funding This work was partly supported by UNLP (11X/690), CONICET (PIP 00340), and ANPCyT (PICT 2014-2223) from Argentina and CTQ2015-64561-R from Spain.

\section{Compliance with ethical standards}

Conflict of interest All the authors declare that they have no conflict of interest.

Ethical approval The animal study was conducted in accordance with the Guide for the Care and Use of Laboratory Animals (National Research Council, USA 2002. Laboratory Animals. A.A Tuffery, 1995. London: John Wiley). All efforts were made to minimize animal suffering, to decrease the number of animals used, and to utilize possible alternatives to in vivo techniques.

Research involving human participants This article does not contain any studies with human participants performed by any of the authors.

\section{References}

1. Kelland L (2007) The resurgence of platinum-based cancer chemotherapy. Nat Rev Cancer 7:573-584. https://doi.org/10.1038/ $\operatorname{nrc} 2167$

2. Yamamoto N, Tsuchiya H (2013) Chemotherapy for osteosarcoma-where does it come from? What is it? Where is it going? Expert Opin Pharmacother 14:2183-2193. https://doi. org/10.1517/14656566.2013.827171

3. Gorlick R, Khanna C (2010) Osteosarcoma. J Bone Miner Res 25:683-691. https://doi.org/10.1002/jbmr.77

4. Tsuchiya H, Tomita K, Mori Y et al (1999) Marginal excision for osteosarcoma with caffeine assisted chemotherapy. Clin Orthop Relat Res 358:27-35

5. Bode AM, Dong Z (2007) The enigmatic effects of caffeine in cell cycle and cancer. Cancer Lett 247:26-39. https://doi. org/10.1016/j.canlet.2006.03.032

6. Hattinger CM, Fanelli M, Tavanti E et al (2015) Advances in emerging drugs for osteosarcoma. Expert Opin Emerg Drugs. https://doi.org/10.1517/14728214.2015.1051965

7. Durnali A, Alkis N, Cangur S et al (2013) Prognostic factors for teenage and adult patients with high-grade osteosarcoma: an analysis of 240 patients. Med Oncol 30:624. https://doi.org/10.1007/ s12032-013-0624-6

8. Holen I, Coleman RE (2010) Bisphosphonates as treatment of bone metastases. Curr Pharm Des 16:1262-1271

9. McClung M, Harris ST, Miller PD et al (2013) Bisphosphonate therapy for osteoporosis: benefits, risks, and drug holiday. Am J Med 126:13-20. https://doi.org/10.1016/j.amjmed.2012.06.023

10. Xue Z, Lin M, Zhu J et al (2010) Platinum(II) compounds bearing bone-targeting group: synthesis, crystal structure and antitumor activity. Chem Commun 46:1212. https://doi.org/10.1039/b9222 $22 \mathrm{~g}$

11. Igarashi K, Yamamoto N, Hayashi K et al (2015) Effectiveness of two novel anionic and cationic platinum complexes in the treatment of osteosarcoma. Anticancer Agents Med Chem 15:390-399

12. Johnstone TC, Suntharalingam K, Lippard SJ (2016) The next generation of platinum drugs: targeted Pt(II) agents, nanoparticle delivery, and Pt(IV) prodrugs. Chem Rev 116:3436-3486. https ://doi.org/10.1021/acs.chemrev.5b00597

13. Prachayasittikul V, Prachayasittikul S, Ruchirawat S, Prachayasittikul V (2013) 8-Hydroxyquinolines: a review of their metal chelating properties and medicinal applications. Drug Des Devel Ther 7:1157-1178. https://doi.org/10.2147/DDDT.S49763

14. Afzal O, Kumar S, Haider MR et al (2015) A review on anticancer potential of bioactive heterocycle quinoline. Eur J Med Chem 97:871-910. https://doi.org/10.1016/j.ejmech.2014.07.044 
15. Albrecht M, Fiege M, Osetska O (2008) 8-Hydroxyquinolines in metallosupramolecular chemistry. Coord Chem Rev 252:812-824. https://doi.org/10.1016/j.ccr.2007.06.003

16. Martín Santos C, Cabrera S, Ríos-Luci C et al (2013) Novel clioquinol and its analogous platinum complexes: importance, role of the halogen substitution and the hydroxyl group of the ligand. Dalton Trans 42:13343-13348. https://doi.org/10.1039/c3dt51720a

17. Page H, Flood P, Reynaud EG (2013) Three-dimensional tissue cultures: current trends and beyond. Cell Tissue Res 352:123-131. https ://doi.org/10.1007/s00441-012-1441-5

18. Ho WY, Yeap SK, Ho CL et al (2012) Development of multicellular tumor spheroid (MCTS) culture from breast cancer cell and a high throughput screening method using the MTT assay. PLoS One 7:e44640. https://doi.org/10.1371/journal.pone.0044640

19. Friedrich J, Seidel C, Ebner R, Kunz-Schughart L (2009) Spheroidbased drug screen: considerations and practical approach. Nat Protoc 4:309-324. https://doi.org/10.1038/nprot.2008.226

20. Alderden RA, Mellor HR, Modok S et al (2007) Elemental tomography of cancer-cell spheroids reveals incomplete uptake of both platinum(II) and platinum(IV) complexes. J Am Chem Soc 129:13400-13401. https://doi.org/10.1021/ja076281t

21. Modok S, Scott R, Alderden RA et al (2007) Transport kinetics of four- and six-coordinate platinum compounds in the multicell layer tumour model. Br J Cancer 97:194-200. https://doi.org/10.1038/ sj.bjc.6603854

22. Price JH, Williamson AN, Schramm RF, Wayland BB (1972) Palladium(II) and platinum(II) alkyl sulfoxide complexes. Examples of sulfur-bonded, mixed sulfur- and oxygen-bonded, and totally oxygen-bonded complexes. Inorg Chem 11:1280-1284. https://doi. org/10.1021/ic50112a025

23. Okajima T, Nakamura K, Zhang H et al (1992) Sensitive colorimetric bioassays for insulin-like growth factor (IGF) stimulation of cell proliferation and glucose consumption: use in studies of IGF analogs. Endocrinology 130:2201-2212. https://doi.org/10.1210/ endo.130.4.1372238

24. Mosmann T (1983) Rapid colorimetric assay for cellular growth and survival: application to proliferation and cytotoxicity assays. J Immunol Methods 65:55-63

25. Singh NP, McCoy MT, Tice RR, Schneider EL (1988) A simple technique for quantitation of low levels of DNA damage in individual cells. Exp Cell Res 175:184-191

26. Butenko N, Isabel A, Nouri O et al (2009) DNA cleavage activity of V IV O (acac) 2 and derivatives. 103:622-632. https://doi. org/10.1016/j.jinorgbio.2009.01.003

27. Bernadou J, Pratviel G, Bennis F et al (1989) Potassium monopersulfate and a water-soluble manganese porphyrin complex, $[\mathrm{Mn}(\mathrm{TMPyP})](\mathrm{OAc}) 5$, as an efficient reagent for the oxidative cleavage of DNA. Biochemistry 28:7268-7275

28. Leon IE, Di Virgilio a L, Porro V et al (2013) Antitumor properties of a vanadyl(IV) complex with the flavonoid chrysin [VO(chrysin)2EtOH $] 2$ in a human osteosarcoma model: the role of oxidative stress and apoptosis. Dalton Trans 42:11868-11880. https ://doi.org/10.1039/c3dt50524c

29. León IE, Cadavid-Vargas JF, Resasco A et al (2016) In vitro and in vivo antitumor effects of the VO-chrysin complex on a new three-dimensional osteosarcoma spheroids model and a xenograft tumor in mice. JBIC J Biol Inorg Chem 21:1009-1020. https://doi. org/10.1007/s00775-016-1397-0

30. ElBayoumi TA, Torchilin VP (2009) Tumor-targeted nanomedicines: enhanced antitumor efficacy in vivo of doxorubicin-loaded, long-circulating liposomes modified with cancer-specific monoclonal antibody. Clin Cancer Res 15:1973-1980. https://doi. org/10.1158/1078-0432.CCR-08-2392

31. Pregosin PS (1982) Platinum-195 nuclear magnetic resonance. Coord Chem Rev 44:247-291. https://doi.org/10.1016/S0010 $-8545(00) 80523-8$
32. León IE, Di Virgilio AL, Barrio DA et al (2012) Hydroxylamidoamino acid complexes of oxovanadium(V). Toxicological study in cell culture and in a zebrafish model. Metallomics 4:1287-1296. https://doi.org/10.1039/c2mt20091k

33. Flocke LS, Trondl R, Jakupec MA, Keppler BK (2016) Molecular mode of action of NKP-1339 — a clinically investigated ruthenium-based drug - involves ER- and ROS-related effects in colon carcinoma cell lines. Invest New Drugs 34:261-268. https://doi. org/10.1007/s10637-016-0337-8

34. Terenzi A, Pirker C, Keppler BK, Berger W (2016) Anticancer metal drugs and immunogenic cell death. J Inorg Biochem 165:71-79. https://doi.org/10.1016/j.jinorgbio.2016.06.021

35. Kamogashira T, Fujimoto C, Yamasoba T (2015) Reactive oxygen species, apoptosis, and mitochondrial dysfunction in hearing loss. Biomed Res Int 2015:617207. https://doi.org/10.1155/2015/617207

36. Slimen IB, Najar T, Ghram A et al (2014) Reactive oxygen species, heat stress and oxidative-induced mitochondrial damage. A review. Int J Hyperthermia 30:513-523. https://doi.org/10.3109/02656 736.2014 .971446

37. Herr I, Debatin KM (2001) Cellular stress response and apoptosis in cancer therapy. Blood 98:2603-2614

38. Mayer B, Oberbauer R (2003) Mitochondrial regulation of apoptosis. News Physiol Sci 18:89-94

39. Walzl A, Unger C, Kramer N et al (2014) The resazurin reduction assay can distinguish cytotoxic from cytostatic compounds in spheroid screening assays. J Biomol Screen 19:1047-1059. https://doi. org/10.1177/1087057114532352

40. Chen JL, Steele TWJ, Stuckey DC (2015) Modeling and application of a rapid fluorescence-based assay for biotoxicity in anaerobic digestion. Environ Sci Technol 49:13463-13471. https://doi. org/10.1021/acs.est.5b03050

41. Schreiber-Brynzak E, Klapproth E, Unger C et al (2015) Threedimensional and co-culture models for preclinical evaluation of metal-based anticancer drugs. Invest New Drugs 33:835-847. https ://doi.org/10.1007/s10637-015-0260-4

42. Shahid F, Farooqui Z, Khan F (2018) Cisplatin-induced gastrointestinal toxicity: an update on possible mechanisms and on available gastroprotective strategies. Eur J Pharmacol 827:49-57. https://doi. org/10.1016/j.ejphar.2018.03.009

43. Perše M, Večerić-Haler Ž (2018) Cisplatin-induced rodent model of kidney injury: characteristics and challenges. Biomed Res Int 2018:1-29. https://doi.org/10.1155/2018/1462802

44. Qin Q-P, Chen Z-F, Qin J-L et al (2015) Studies on antitumor mechanism of two planar platinum(II) complexes with 8-hydroxyquinoline: synthesis, characterization, cytotoxicity, cell cycle and apoptosis. Eur J Med Chem 92:302-313. https://doi.org/10.1016/j. ejmech.2014.12.052

45. Dilruba S, Kalayda GV (2016) Platinum-based drugs: past, present and future. Cancer Chemother Pharmacol 77:1103-1124. https:// doi.org/10.1007/s00280-016-2976-Z

46. Roberts NB, Wadajkar AS, Winkles JA et al (2016) Repurposing platinum-based chemotherapies for multi-modal treatment of glioblastoma. Oncoimmunology 5:e1208876. https://doi. org/10.1080/2162402X.2016.1208876

47. Ruggiero A, Trombatore G, Triarico S et al (2013) Platinum compounds in children with cancer. Anticancer Drugs 24:1007-1019. https://doi.org/10.1097/CAD.0b013e3283650bda

48. Brozovic A, Ambriović-Ristov A, Osmak M (2010) The relationship between cisplatin-induced reactive oxygen species, glutathione, and BCL-2 and resistance to cisplatin. Crit Rev Toxicol 40:347-359. https://doi.org/10.3109/10408441003601836

49. Fujii H, Honoki K, Tsujiuchi T et al (2009) Sphere-forming stemlike cell populations with drug resistance in human sarcoma cell lines. Int J Oncol 34:1381-1386

50. Langdon SP (2012) Animal modeling of cancer pathology and studying tumor response to therapy. Curr Drug Targets $13: 1535-1547$ 